\title{
9 an EMPIRICAL INVESTIGATION OF THE POTENTIAL OF RFID TECHNOLOGY TO ENHANCE SUPPLY CHAIN AGILITY ${ }^{1}$
}

\author{
Anthony Vance \\ Brigham Young University \\ Provo, UT U.S.A.
}

\begin{abstract}
This empirical study examines the potential of RFID technology to increase the business agility and coordination of inventory supply chain systems. The bullwhip effect is a logistics management phenomenon in supply chain systems that is characterized by a lack of business agility. This study examines the potential of radio frequency identification (RFID) technology to increase the business agility and coordination of inventory supply chain systems, greatly reducing the bullwhip effect through timely information provided throughout the supply chain. An experiment of one group of 15 tearns using a simulated RFID-enabled supply chain system compared mean team costs with those of a control group of 15 teams, providing empirical evidence that RFIDtechnology can increase a supply chain's business agility, as manifested by a reduction in inventory holding and stockout costs.
\end{abstract}

\section{INTRODUCTION}

This study examines the potential of radio frequency identification (RFID) technology to increase the business agility of inventory supply chains by mitigating what is known in supply chain management literature as the "bullwhip effect" (Lee et al. 1997b). RFID technology has received much attention in recent years as retailers and manufacturers such as Wal-Mart, Gillette, and Target have committed themselves to implementing this technology into their supply chain information systems. Logistics literature suggests that RFID technology increases the agility of supply chain systems and gives companies a competitive advantage (Kinsella 2003). RFID tags are analogous

'This research was sponsored by the Kevin and Debra Rollins Center for eBusiness at Brigham Young University. 
to barcodes that wirelessly transmit their serial number to in-store scanning machines (Atock, 2003; Robertson, et al. 1999). This automatic self-identification process is a great improvement over traditional barcodes. Traditional barcodes typically require employees to physically scan each item. Because traditional barcodes require a line-ofsight view of a barcode in order to scan the serial number, barcode scanning is laborintensive and is usually only performed at the checkout register (Sarma et al. 2001). RFID chips add a nominal cost to each item but enable supply chain information systems to easily scan items throughout the supply chain, potentially enabling managers to visualize exactly how much inventory exists in the supply chain, and therefore know how much more inventory needs to be purchased or produced.

Proponents claim that RFID technology can potentially enable supply chain managers to overcome problems caused by imperfect or insufficient information inherent in current inventory management systems (RFID Forum 2003). The bullwhip effect is a well-known problem within supply chain management literature that directly relates to business agility from an Information Systems standpoint (Bowersox et al. 2000; Lee et al. 1997b). Information systems can increase business agility by providing businesses with current, relevant information from which managers can make better informed decisions. The bullwhip effect is a supply chain phenomenon in which imperfect inventory information is amplified as it is transmitted through the supply chain, resulting in increasingly inefficient inventory order levels. In a supply chain system with low coordination, suppliers gauge consumer demand by observing orders made by retailers. However, retailer orders are usually inflated due to safety stock - an inventory buffer used to allow for fluctuations in consumer demand (Sterman 1989). Retailer orders then offer a distorted view of consumer demand. The distortion of actual consumer demand worsens as each successive tier in a supply chain adds its own level of safety stock to the orders it requests. By the time the information reaches the top of the supply chain, the information is grossly distorted and most adversely affects toplevel manufacturers (Lee et al. 1997a). In the bullwhip analogy, top-level manufacturers represent the tip of the bullwhip that is finally cracked.

The term bullwhip effect was coined by Proctor and Gamble management who noticed an amplification of information distortion as order information traveled up the supply chain (Lee et al. 1997b). However, amplification of information distortion was known to supply chain management researchers long before the term bullwhip effect came into common use. For example, in 1958, Forrester presented a number of simulated case studies detailing the distortion of order information that occurs along a supply chain. In one computer-simulated study, a 10 percent increase in retail sales caused retailers to increase inventory orders by 10 percent, which in turn was matched by a 16 percent and 28 percent increase in orders by distributors and warehouses respectively. Finally, the manufacturers increased output by 40 percent (Forrester 1958). Forrester concluded that the variation amplification observed in supply chains was due in part to communication delays and distorted information. More recent studies have also pointed to imperfect information as the root cause of the bullwhip effect. One study involved a series of experiments using a role playing game called the Beer Distribution Game, which was developed at Massachusetts Institute of Technology (Sterman 1989). In this study, Sterman used the Beer Distribution Game to show how using incomplete data to make inventory ordering decisions leads to wide inventory fluctuations in the supply chain. More recently, a study dealing with mathematical 
econometrics showed that demand signal processing, the practice of gauging demand from the order information of the next downstream supply chain member, is a significant factor of the bullwhip effect (Lee et al. 1997a). The above-mentioned studies show that imperfect information in the form of distortion or delays contributes significantly to the bullwhip effect.

Although the technical merits of RFID are well documented, the technology is still emerging and there is little available information that examines the capability of RFID technology to mitigate the bullwhip effect. On the other hand, while many of the studies cited above present theoretical models and simulations examining the bullwhip effect, these studies do not take into account the advantage of the added information now available through RFID technology.

The purpose of the present study was to empirically link previous research on the bullwhip effect to the potential of RFID supply chain information systems to increase supply chain agility and thereby reduce the bullwhip effect. This research employs a simulation intended to reveal the extent of RFID technology's impact on a vertical supply chain system. In so doing, this study helps to establish principles of RFID technology that can be further added to and expanded. RFID technology has the potential to overcome the bullwhip effect's amplified inventory information distortion by providing each tier of a supply chain with accurate, real-time information of inventory allocation within the supply chain. Because this study examines the affect of enhanced information, the proposed experiment does not involve RFID tags. Instead, a simulation is proposed that mimics an inventory supply chain system that is enabled with RFID technology.

\section{OPERATIONALIZING THE CONSTRUCT OF INVENTORY MANAGEMENT EFFICIENCY}

Because imperfect information is so central to the occurrence of the bullwhip effect, this study proposes that additional information available through the use of RFID technology will enable inventory managers to achieve the construct of regulating inventory stock within an appropriate range, that is, setting "the inflow rate so as to compensate for losses and usage and to counteract disturbances which push the stock away from its desired value" (Sterman 1989, p. 322). In order to operationalize the construct of appropriate inventory regulation, this study used the following two measures:

1. The cost of foregone revenue or stockout costs. Sterman defines stockout costs as "the cost for having a backlog of unfilled orders" (p. 326). Stockout costs are determined as the total lost sales revenue for every inventory unit on back order.

2. The cost of unnecessary inventory holding costs, determined as the holding cost of all inventory units that are not sold during a given sales period (Sterman 1989).

Combined, the above measures help operationalize the appropriate regulation of inventory because, in order to minimize stockout and holding costs, a firm must keep 
inventory levels within the optimum range. The more efficient a supply chain, the less the combined cost of holding costs and stockout costs. Conversely, the less efficient an inventory supply chain is, the higher the holding and stockout costs will be. This study's construct related question is: Will the use of RFID chips enable supply chains to better regulate inventory levels within the optimum (most cost efficient range)?

The operational question that follows the construct is: Will use of RFID chips enable supply chains to minimize the inventory holding and stockout costs?

Supply chain systems with additional information resulting from the usage of an RFID technology application should have statistically significant lower-average inventory stockout costs as well lower-average inventory holding costs than those managers with traditional barcode systems and limited inventory information. Further, RFIDenabled supply chain systems should not experience the amplification of order information distortion that is typical of the bullwhip effect (Lee et al. 1997a). Highertier supply chain members such as wholesalers and manufacturers should have roughly equal levels of inventory holding and stockout costs. A more equal variance in inventory stockout and holding costs among supply chain tiers should be reflected by a lower standard deviation of individual supply chain tier holding and stockout costs than the standard deviation of supply chain systems without RFID technologies. Therefore, the present study proposes the following hypotheses:

H0: RFID-enabled supply chain systems that track and display inventory information to member supply chain tiers will not have lower mean inventory costs than traditional supply chain systems.

H1: RFID-enabled supply chain systems that track and display inventory information to member supply chain tiers will have lower mean inventory costs than traditional supply chain systems.

\section{METHOD}

To test the above hypothesis, this study employed the Beer Distribution Game, a popular simulation in supply chain literature used to demonstrate how poor information and low coordination of supply chain members causes the bullwhip effect to occur. The Beer Distribution Game was developed at MIT to simulate the bullwhip effect in an experiment, and has been used widely for nearly four decades (Munson et al. 2003).

According to Sterman, the Beer Distribution Game is a "simulated inventory distribution system which contains multiple actors, feedbacks, nonlinearities, and time delays. The interaction of individual decisions with the structure of the simulated firm produces aggregate dynamics which systematically diverge from optimal behavior" ( $p$. 321). In short, the Beer Distribution Game repeatedly demonstrates how the bullwhip effect can result from imperfect information. This study involves an experiment that employs a traditional Beer Distribution Game as used by Sterman for the control group, and a modified version of the Beer Distribution Game for the experimental group. 


\subsection{Control Group}

The Beer Distribution Game consists of a simplified four-tier supply chain in which a team of four human subjects each play the part of inventory manager for one of four supply chain tiers: retailer, wholesaler, distributor, and factory. Each tier inventory manger orders inventory independently from the other supply chain tier managers using only the inventory order information from the immediate downstream supply chain member. The game is typically played on a board with markers representing inventory evenly distributed throughout the supply chain. However, for this experiment, both control and experimental versions of the Beer Distribution Game were played using a real-time, Wb-based network that allowed four students at four separate computer workstations to act as an integrated supply chain. The level of inventory demand by consumers is simulated by a predefined level of consumer demand that is the same for each instance the Beer Distribution Game is played. As retail inventory levels are depleted through customer sales, the retail inventory manager orders more inventory from the distributor. The distributor in turn orders more inventory from the factory warehouse, and so on. Each tier manager can only use the order information available from the downstream supply chain member. Given varying customer demand, each tier must order a level of safety stock so that costly stockouts do not occur. However, if too much safety stock is on hand, the tier will incur a per-item inventory holding cost. The holding cost for each item of inventory is $\$ 2$, while the stockout cost per inventory item is $\$ 4$. The object of the game is to minimize holding and stockout costs as a team, or in other words, become an efficient supply chain.

In administering the game, each subject is randomly assigned a role as a retailer, wholesaler, distributor, or factory. After the rules of the game are explained, the game's distribution channel is initialized in equilibrium. Each tier has an inventory of 12 cases, and the supply chain throughput is four cases per week to match consumer demand that is also initially four cases per week. During the first four rounds, consumer demand remains the same as the subjects become accustomed to ordering for their respective tier. For the first three rounds, the subjects are instructed to order four cases; in the fourth round subjects can order any nonzero amount. However, in the fifth round, there is an unannounced increase in consumer demand to eight cases. This increase in demand creates a disequilibrium in the supply chain to which the subjects must adjust. In the game's instructions, the subjects are told the game will continue for 50 rounds; however, Sterman suggests halting the game after round 30 to avoid horizon effects.

Each tier has only local information available: each subject can only see the order size of the next downstream tier. In Sterman's study of 48 teams (consisting of 192 subjects), invariably customer demand information represented by retail orders became distorted as each successive tier added a measure of safety stock to the order. The information distortion within the supply chain caused broad swings in inventory levels from inventory shortages to surpluses, with always the top-most tier (factory) being most affected. At the end of all of the rounds, the holding costs and stockout costs are tallied for the team as a whole (all four tiers) and recorded.

From the above description of the mechanics of the Beer Distribution Game, five contributing factors to the occurrence of the bullwhip effect can be seen. These are 
- Delay in signal. The time required for an inventory order to arrive at the next upstream tier (four rounds).

- Delay in inventory to arrive. The time required for ordered inventory to reach the next downstream tier (an additional four rounds).

- Limited global information. Subjects are ignorant of how much inventory is available at other tiers as well as the level of demand facing other tiers.

- An unexpected 100 percent increase in customer demand. The inventory demanded by the consumer jumps from four units of inventory to eight where it subsequently remains until the end of the game.

- Uncoordinated order decisions. Subjects cannot communicate with one another, thereby preventing team strategies to form.

Each of the above five factors contributes to the occurrence of the bullwhip effect and together make the occurrence of the bullwhip effect almost inevitable and practically impossible to mitigate. In fact, in Sterman's observations of performing the Beer Distribution Game over the span of multiple decades revealed that the bullwhip effect always occurred to some degree when the game was administered.

\subsection{Experimental Group}

The experimental group played the Beer Distribution Game in precisely the same manner of execution as the control group, with the exception that the experimental computer program simulated the use of RFID technology by displaying the flow of all inventory cases from the lowest supply chain tier (retailer) to the highest tier (factory). Not only does this added information provide each supply chain member with real-time inventory information, but in effect a continuous consciousness of the whole supply chain is created. This full awareness of the supply chain should greatly increase the agility of the supply chain as a whole as inventory managers are able to make better inventory decisions. Because of the above advantages, it is hypothesized that the bullwhip effect in the experimental group will be much less acute than in the control group.

By simulating an RFID-enabled supply chain within the model of the Beer Distribution Game, two of the five factors contributing to the occurrence of the bullwhip effect are removed: limited global information and, following as a natural consequence, the delay of signal. Given the current literature on the potential of RFID technology to provide both instantaneous and global supply chain in formation (Kinsella, 2003; Sarma et al. 2000), removing these two factors seems consistent with the capabilities of proposed RFID-enabled supply chain systems.

However, the remaining three contributing factors to the occurrence of the bullwhip effect are held constant, namely the delay in the receipt of inventory, the unexpected increase in consumer demand, and the requirement that inventory ordering decisions be made independently, without communication among fellow supply chain tier members. 
These three factors significantly contribute to the occurrence of the bullwhip effect and, therefore, the utility of the Beer Distribution Game to produce the bullwhip effect should remain.

\subsection{Sample}

The sample for this study was 120 undergraduate students at a private university in the western United States drawn from two large introductory classes in Accounting and Information Systems. Each student was randomly placed in a team with three other students. Because both experimental and control group versions of the Beer Distribution Game were played using networked computers, subjects did not know who their teammates were. Altogether, the subjects were organized into 30 teams of four -15 teams for the control group and 15 teams for the experimental group.

\section{RESULTS}

At round 30, each team's combined holding and stockout costs were totaled for all supply chain tiers for all previous rounds. This aggregation produced one single inventory cost total for each team. An independent samples f-test revealed that mean costs for the experimental group simulating the RFID technology approach were significantly less than those in the control group ( $\mathrm{f}=4.706, \mathrm{p}=.039$ ). Table 1 presents the exploratory statistics for the two; note the difference in the means and standard deviations.

The resulting mean for the control group was affected by an outlier team with an unusually high score that raised the control group's mean substantially, from approximately $\$ 76,000$ dollars to nearly $\$ 168,000$ dollars. However, despite this outlier

Table 1. Exploratory Statistics

\begin{tabular}{|c|r|r|r|}
\hline Group & & Statistic & Std. Error \\
\hline Experimental & Mean & $\$ 17,536.67$ & 2886.36 \\
& Median & $\$ 12,480.00$ & \\
& Std. Deviation & $\$ 11,178.81$ & \\
Minimum & $\$ 6,340.00$ & \\
& Maximum & $\$ 42,860.00$ & \\
\hline Control & Range & $\$ 36,520.00$ & \\
& Mean & $\$ 167,927.47$ & 93109.72 \\
& Median & $\$ 54,638.00$ & \\
& Std. Deviation & $\$ 360.612 .40$ & \\
& Minimum & $\$ 16.090 .00$ & \\
& Maximum & $\$ 1,447,702.00$ & \\
& Range & $\$ 1,431,612.00$ & \\
\hline
\end{tabular}


Table 2. F-Test of Experimental and Control Group Differences

\begin{tabular}{|c|l|c|c|c|c|c|}
\hline & Group & $\mathbf{N}$ & Mean & Std. Deviation & $\mathbf{F}$ & Sig. \\
\hline \multirow{2}{*}{ Costs } & Experimental & 15 & $\$ 17,536.6667$ & $\$ 11,178.80509$ & 4.706 & .039 \\
\cline { 2 - 8 } & Control & 15 & $\$ 167,927.4667$ & $\$ 360,612.40109$ & & \\
\hline
\end{tabular}

and resulting greatly increased within-group variance, the f-test found significant between-group difference at the .05 level (see Table 2 ).

\section{DISCUSSION}

This study indicates that RFID technology has significant potential to increase business agility in supply chain systems. From the results, it is apparent that the RFIDsimulated experimental group was enabled to better adapt to the change in consumer demand as well as to each supply chain member's independent inventory orders. Because of continuous supply chain information available from the production of inventory to its eventual sale, the experimental RFID-simulated group was able to act more closely as an integrated whole rather than four disjointed units or parts. Without this added information, it was difficult for control group supply chain members to achieve any level of coordination.

From the perspective of business agility, RFID-technology holds tremendous promise for manufacturing supply chains. Managing inventory through several distinct and often divergent supply chain tiers is a major challenge. With such conditions, any coordination among supply chain tiers is a victory. However, given the volatile market place and increasing pressure from competitors, inventory supply chains must become increasingly agile in order to remain competitive and relevant to the consumer's needs. The promise of RFID technology is to enable a supply chain to act as a cohesive unit-to readily provide inventory information throughout the supply chain, from inventory creation to its final sale to the consumer (Atock, 2003; Kinsella, 2003; Robertson et al. 1999).

The validity of above study is necessarily limited by the relatively small team sample size. A planned expansion of the provided sample may help to strengthen the conclusion and internal validity of this study. Similarly, studies of RFID-technology applied to different business applications would certainly strengthen this study's external validity. As an abstract simulation, the RFID-enabled Beer Distribution Game is obviously limited in its generalizability. However, on this point, Sterman gave this insight into his initial research utilizing the Beer Distribution Game:

The experiment, despite its rich feedback structure, is vastly simplified compared to the real world. To what extent do the experimental conditions and results apply? First, would subjects' behavior differ if customer demand follows a more realistic pattern, e.g. noise and seasonality? The order decisions of many subjects were in fact noisy and cyclic. (p. 326) 
Sterman also explains that although managers in the real world have access to more inventory information than the subjects in the experiment, "information in the real world is often out of date, noisy, contradictory and ambiguous" (p. 326). Therefore, the generalizability of this study, although limited, may be greater than it ostensibly appears.

A further limitation to the validity of the present study is the lack of real-world, RFID-enabled supply chain data to verify the results of the simulated RFID-enabled supply chain of the experimental group. The validity of the traditional Beer Distribution Game in describing the bullwhip effect has been strengthened by agreement with expert opinion of supply chain domain professionals and data observed from the bullwhip effect in actual supply chains. The findings of the present study can also be strengthened by similar calibration to data provided by actual RFID-enabled supply chain systems when such systems become more widely implemented.

Given the above-mentioned expectation for RFID technology to revolutionize the supply chain system, some may find little surprise with the above results. Indeed, the idea that timely and pertinent information can enhance the efficiency of a supply chain is not only intuitive, but also foundational to logistic information systems and the field of Information Systems in general. However, despite how axiomatic the above results may appear, the potential of RFID technology to increase business agility in supply chains should nevertheless be explored and empirically studied. If the above-stated predictions are even partially accurate, RFID technology merits a thorough understanding through empirical study as use of this technology unfolds. Without such carefully tested knowledge, RFID technology may fall into the category of a fad and be misapplied, and the promise of greater business agility of a supply chain as a whole may take longer to realize.

\section{REFERENCES}

Atock, C. "Where's My Stuff?," Manufacturing Engineer (82:2), 2003, pp. 24-27

Bowersox, D. J., Closs, D. J., and Stank, T. P. "Ten Mega-Trends that Will Revolutionize Supply Chain Logistics," Journal of Business Logistics (21:2), 2000, pp. 6-10.

Forrester, J. W. "Industrial Dynamics: A Major Breakthrough for Decision Makers," Harvard Business Review (4:36), July-August 1958, pp. 37-66.

Kinsella, B. "The Wal-Mart Factor," Industrial Engineer (35:11), November 2003, pp. 32-36.

Lee, H. L., Padmanabhan, V., and Whang, S. "The Bullwhip effect in Supply Chains," Sloan Management Review (38:3), 1997a, pp. 93-102.

Lee, H. L., Padmanabhan, V., and Whang, S. "Information Distortion in a Supply Chain: The Bullwhip Effect," Management Science (43:4), 1997b, pp. 546-548.

Munson, C. L., Hu. J., and Rosenblatt, M. J. "Teaching the Costs of Uncoordinated Supply Chains," Interfaces (33:3), 2003, pp. 24-39.

RFID Forum. Logistics \& Transport Focus (5:1), July-August 2003, p. 49

Robertson, I. D., Blewett, M., Amin, J., Butt, I., Donnelly, F., Harwood, P., and Woolven, A. "A Simple Radio-Frequency System for Asset Tracking Within Buildings," IEE Colloquilum (23), October 25, 1999, pp. 29-34.

Sarma, S., Brock D. L., and Ashton, K. "The Networked Physical World: Proposals for Engineering the Next Generation of Computing, Commerce, and Automatic-Identification," Massachusetts Institute of Technology Auto-ID Center White Paper, October 1, 2000 (available online at http://www.autoidlabs.org/whitepapers/MIT-AUTOID-WH-001.pdf). 
Sarma. S., Brock, D. L., Engels, D. "Radio Frequency Identification and the Electronic Product Code," IEEE Micro (21:6), 2001, pp. 50-54.

Sterman, J. "Modeling Managerial Behavior: Misperceptions of Feedback in a Dynamic Decision Making Experiment," Management Science (35:3), 1989, pp. 321-339.

\section{ABOUT THE AUTHOR}

Anthony Vance received a master's degree from Brigham Young University in Information Systems Management in 2004. Currently, Anthony works as a consultant in Deloitte's Enterprise Risk Services division where he performs Sarbanes-Oxley IT assessments as well as fraud prevention data analyses in relation to SAS 99. Anthony lives in Atlanta with his wife Sarah and their one-year-old son, Ryan. Anthony can be reached at Anthony.Vance@byu.edu. 